\title{
Levantamento e identificação dos aspectos epidemiológicos da raiva canina no município de Cuiabá - MT
}

\section{Survey and identification of the epidemiological aspects of canine rabies in the city of Cuiabá-MT}

\author{
Darci Lara Perecin NOCITI ${ }^{1}$, Ricardo Perecin NOCITI ${ }^{2}$, Simone Pereira VALERIANO ${ }^{3}$ \\ ${ }^{1}$ Faculdade de Agronomia, Medicina Veterinária e Zootecnia da Universidade Federal de Mato Grosso, Cuiabá - MT, Brasil \\ ${ }^{2,3}$ Médico Veterinário Autônomo
}

\begin{abstract}
Resumo
Reconhecida desde a antiguidade, a raiva é uma infecção aguda do sistema nervoso central que acomete mamíferos, sendo causada por um RNA vírus da família Rabidoviridae, gênero Lyssavírus. O Brasil, desde a implantação do programa de controle da raiva em áreas urbanas, vem apresentando um declínio de casos de raiva em cães e em seres humanos. Em Cuiabá, as atividades realizadas pelo Centro de Controle de Zoonoses voltadas para o controle da raiva como: vacinação antirrábica animal, bloqueios de foco, captura de animais errantes, entre outros, permitiu o bloqueio da circulação do vírus na espécie canina. Desde 2008, o município de Cuiabá não registra nenhum caso da doença na espécie canina. Com o objetivo de conhecer a distribuição temporal da raiva canina em Cuiabá- MT, assim como identificar os aspectos epidemiológicos dos cães infectados pelo vírus rábico e verificar as medidas de profilaxia para a raiva canina, adotadas pelo Centro de Controle de Zoonose do município de Cuiabá no período de janeiro de 2002 a dezembro de 2008, realizou-se o presente estudo. Para o estudo observacional descritivo foi empregado o banco de dados referente à série histórica do CCZ e do Laboratório de Apoio a Saúde Animal - LASA ambos situados no município de Cuiabá- MT. O período de estudo foi de janeiro de 2002 a dezembro de 2008. Neste período foram examinadas 1021 amostras de cérebro de cães, destas 8,71\% (89/1021) foram positivas e 91,29\% (932/1021) negativas para a raiva. Os meses de maior incidência da doença foram os meses de janeiro 15,05\% (14/93), fevereiro 12,5\% (9/72), março 12,5\% (9/72), abril 14,14\% (9/72) e dezembro 13,69\% (10/73). O maior número de cães doentes era macho 59,55\% (53/89) com idade acima de dois anos 50,55\% (45/89) e não domiciliados 67,41\% (60/89). Em relação à imunoprofilaxia, a maioria dos cães $99,63 \%$ foi vacinada em campanhas. A cobertura vacinal ficou acima dos $80 \%$ exceto em 2006. Entre os animais que apresentaram a enfermidade o maior número, 67,41\% (60/89), foi de cães não domiciliados, os chamados cães errantes. O percentual de cães domiciliados infectados pelos VR foi igual a 32,58\% (29/89). As campanhas de vacinação, portanto, são fundamentais para a imunização do maior número de animais possível e a sociedade deve se conscientizar sobre a importância da raiva e as medidas que devem ser tomadas para controlá-la.
\end{abstract}

Palavras-chave: Cães. Cuiabá. Raiva. Vacina.

\begin{abstract}
Known since the ancient times, the rabies is an acute infection of the central nervous system that affects mammals, caused by an RNA virus of the Rhabidoviridae family, Lyssavirus gender. Since the implantation of the urban area rabies control program in Brazil the number of cases in dogs and human have shown a decrease. In Cuiabá, the efforts to control the rabies, such as animal vaccination, focus isolation, capture of nomad animals and others realized by the Zoonosis Control Center has leaded to locking in the viral circulation in the canine species. Since 2008, zero cases of the disease in dogs were reported. In order to know the temporal distribution of canine rabies in Cuiabá - MT and identify the epidemiologic aspects of the rabies's infected dogs, and verify the canine rabies's profilatic actions of the Zoonosis Control Center of the city of Cuiabá, during the period of January, 2002 to December , 2008, the present study was performed. The historic data base from Cuiabá - MT was obtained at the Zoonosis Control Center and at the Animal Health Support Laboratory and used to perform the descriptive and observational study. During the performance of the study, 1021 samples of canine's brains were examined, 8,71\% (89/1021) of them were positive and $91,29 \%(932 / 1021)$ of them were negative for the rabies test. The Months with higher incidence were January with 15,05\% (14/93), February with 12,5\% (9/72), March with 12,5\% (9/72), April with 14,14\% (9/72) and December with $13,69 \%$ (10/73). The major part of the infected dogs were males with 59,55\% (53/89) older than two years old 50,55\% $(45 / 89)$ and were nomads animals $67,41 \%(60 / 89) .99,63 \%$ of the infected dogs were vaccinated in anti rabies vaccination campaigns. The vaccinal cover was higher than $80 \%$, except in 2006 . The percentual of the domiciled infected dogs by the rabies virus were $32,58 \%$ (29/89). Therefore the vaccination campaigns are essential for the immunization of a higher number of animals, and the society must be awareabout the importance of rabies and about the actions to control it.
\end{abstract}

Keywords: Dogs. Cuiabá. Rabies. Vaccine.

Correspondência para:

Darci Lara Perecin Nociti

Av. Fernando Correa da Costa, 2367, Bairro Boa Esperança
CEP: 78060-900, Cuiabá, MT, Brasil

Recebido: 18/10/2010

Aprovado: 09/11/2011 


\section{Introdução}

A raiva é uma doença letal, causada pelo vírus rábico do gênero Lyssavirus, família Rhabdoviridae, caracterizada por sintomas de comprometimento do sistema nervoso central, sob a forma de encefalite ${ }^{1}$.

A epidemiologia da raiva depende claramente da passagem deste vírus de um indivíduo infectado a outro suscetível. A transmissão da doença se dá predominantemente pela inoculação do vírus presente na saliva e secreções do animal infectado, em consequência de mordedura, lambedura, ferimento de mucosa ou arranhões ${ }^{2,3,4}$. São conhecidos dois ciclos epidemiológicos de raiva: a raiva urbana, mantida por cães e gatos, e a raiva rural, mantida por animais silvestres. O ciclo urbano da doença continua sendo o mais importante para a raiva humana. Em áreas urbanas, nas situações onde as medidas de controle não atingem seu objetivo de interromper a cadeia de transmissão, a espécie de maior relevância epidemiológica para a transmissão do vírus é o cão, principal reservatório e fonte de infecção $0^{4}$.

Por ter como reservatório na natureza um grande número de espécies animais, o controle da raiva passa a exigir a aplicação de medidas dirigidas à redução da circulação do vírus naquela espécie de maior importância epidemiológica, numa determinada região geográfica ${ }^{5}$.

Mesmo nas áreas onde a raiva canina foi erradicada, esta pode ser reintroduzida por animais silvestres, se a população de cães não é imunizada adequadamente ${ }^{2}$.

O programa de profilaxia da raiva, criado em 1973 pelo Ministério da Saúde (MS), prevê como uma das principais medidas de controle da doença, a vacinação em massa de cães e gatos com o objetivo de se deter o ciclo de transmissão do vírus ${ }^{6}$.

As intervenções relacionadas ao animal, no que se refere à profilaxia da raiva, são de responsabilidade do Centro de Controle de Zoonoses e entre elas se incluem não apenas a observação, mas também a vacinação em massa, a captura de cães errantes, além de programas relacionados à educação e saúde ${ }^{6}$. Com o objetivo de conhecer a distribuição temporal da raiva canina em Cuiabá MT, assim como identificar os aspectos epidemiológicos dos cães infectados pelo vírus rábico e verificar as medidas de profilaxia à raiva canina adotadas pelo Centro de Controle de Zoonose da cidade de Cuiabá, no período de janeiro de 2002 a dezembro de 2008 , realizou-se o presente estudo.

\section{Material e Método}

O estudo observacional descritivo do comportamento da raiva canina foi realizado com base em fonte de dados secundários mensais procedentes do Centro de Controle de Zoonoses e Laboratório de Apoio a Saúde Animal - LASA instituições que atuam na atenção à raiva animal no Município de Cuiabá - MT.

Localizada na Região Centro-Oeste do Brasil, Cuiabá é a capital do Estado de Mato Grosso, e tem um território de $3.971 \mathrm{~km}^{2}$ com uma densidade demográfica de 126,7 habitantes por $\mathrm{km}^{2}$. Enquanto macrorregião estadual, Cuiabá se localiza na denominada Baixada Cuiabana, que é composta pelos municípios: Acorizal, Rosário Oeste, Chapada dos Guimarães, Santo Antônio do Leverger e Várzea Grande acima, além de Barão do Melgaço, Jangada, Poconé, Nossa Senhora do Livramento, Paranatinga, Nova Brasilândia, Gaúcha do Norte e Planalto da Serra ${ }^{7}$.

As atividades econômicas predominantes são o comércio e serviços. Referente à área de saúde, o município de Cuiabá é um dos treze municípios integrantes do Escritório Regional de Saúde de Cuiabá, instância representante da Secretaria Estadual de Saúde, cuja sede encontra-se localizada neste município 7 . Apresentando uma taxa de crescimento anual de $2,04 \%$, a população é de 551.350 habitantes onde 98,6\% (543.631) residem na área urbana ${ }^{8}$. Em 2000, o município contava com 165 unidades públicas/particulares de ensino pré-escolar, 211 de ensino fundamental e 69 de ensino médio?. 
Cerca de 96,0\% da população de Cuiabá recebe água tratada, enquanto o sistema de esgoto atende a 275.000 habitantes (55,0\% da população total) com coleta e destes 148.000 habitantes com coleta e tratamento. Em Cuiabá, são coletadas diariamente 350 toneladas de lixo domiciliar e comercial alcançando uma cobertura de $95,0 \%{ }^{9}$.

O universo da pesquisa foi correspondente as 1021 amostras de cérebro de cães suspeitos de infecção pelo vírus rábico entre janeiro de 2002 a dezembro de 2008.

O estudo foi desenvolvido com base em dados oriundos do Sistema de Vigilância da Raiva, coletados através do livro de registros do Laboratório de Apoio a Saúde Animal - LASA, que é o laboratório de referência para o diagnóstico da raiva em Mato Grosso. No LASA, a relação de material encaminhado para análise é catalogado manualmente, em um livro de registros. Nesse livro, consta o registro do número de amostras enviadas para análise, a data de entrada, a espécie do animal e o resultado final. Para o presente estudo, utilizaram-se dados de janeiro de 2002 a dezembro de 2008.

Utilizaram-se também dados adicionais e complementares a respeito das atividades relacionadas à profilaxia da raiva canina, no mesmo período, realizadas pelo Centro de Controle de Zoonoses (CCZ) da Fundação de Saúde de Cuiabá, órgão que tem como uma de suas atribuições e responsabilidades executar atividades de profilaxia a raiva. Os dados do CCZ foram coletados de sete planilhas do Excel versão 2003; cada planilha possui um banco de dados referente aos anos de 2002, 2003, 2004, 2005,2006, 2007 e 2008. Por meio dessas planilhas, o órgão tem controle de todas as atividades realizadas durante todos os meses, ano a ano.

As variáveis analisadas de acordo com a planilha de dados do Centro de Controle de Zoonoses foram: as de cães vacinados em rotina e campanha, cobertura vacinal, estimativa da população canina, animais capturados e animais eutanasiados. Dos animais positivos por testes de imunofluorescência direta (ID) e prova biológica - Inoculação em Camundongos (IC) para raiva, foram avaliadas as variáveis que caracterizam esses animais tais como: idade, grau de domiciliação e sexo. Os dados do Centro de Controle de Zoonoses foram coletados de registros do seu próprio Setor de Profilaxia da Raiva, sendo processados manualmente. Com base em dados do livro de registro do LASA INDEA - MT, as variáveis analisadas foram: número amostras enviadas ao Laboratório de Apoio à Saúde Animal e número de amostras positivas para Raiva canina. Os dados do livro de registro do LASA foram disponibilizados com a autorização do INDEA - MT, sendo também processados manualmente.

Os resultados foram redigidos no aplicativo Word versão 2007. Para a produção de tabelas e gráficos, foram utilizadas planilhas eletrônicas do programa Excel versão 2007.

\section{Resultados}

Com o encaminhamento de amostras do Sistema Nervoso Central (SNC) de cães para exame laboratorial, permitiu-se que focos de raiva canina fossem registrados, o que possibilitou determinar a distribuição dessas amostras do mês de janeiro de 2002 a dezembro de 2008. No ano de 2002, 143 amostras foram encaminhadas para o diagnóstico laboratorial e desse total $23,07 \%$ (33/143) apresentaram resultado positivo, que representou 3,23\% do total de 1021 amostras enviadas para análise laboratorial no período estudado; esse foi o ano com maior percentual de positividade. Os focos da doença ocorreram nos meses de janeiro (6/8), fevereiro (6/7), março (4/12), abril (6/12), maio (3/24), junho (1/10), agosto (2/8) setembro (2/5), outubro (1/11) e novembro (2/6). Em 2003, das 132 amostras encaminhadas para diagnóstico laboratorial, 14,39\% (19/132) foram positivas ou 1,86\% (19/1021) do total de amostras enviadas para diagnóstico laboratorial. Esse foi o ano com o segundo maior índice de positividade. No ano de 2004, 115 amostras foram envia- 
das, sendo $26,95 \%$ (31/115) positivas, representando $3,03 \%$ (31/1021) do total de amostras enviadas ao laboratório. De acordo com as tabelas 2 e 3, em 2005, das 147 amostras enviadas, 3,40\% (5/147) foram positivas, indicando uma diminuição da incidência da doença a partir desse ano. Os focos ocorreram nos meses de janeiro (2/4), abril (1/13), julho (1/18), dezembro (1/9) e representaram $0,48 \%$ do total de amostras do período estudado. No ano de 2006, 164 amostras foram encaminhadas para análise laboratorial, nesse ano o percentual de positividade foi igual a zero. Em 2007, do total de 126 amostras analisadas, apenas $0,79 \%$ (1/126) foi positivo. Os resultados obtidos em 2008 foram semelhantes aos de 2006, e confirmaram uma elevada diminuição na incidência da doença a partir de 2005. Das 194 amostras, no ano de 2008, nenhuma foi positiva (Tabela 1).

A figura 1 ilustra o declínio da doença na cidade de Cuiabá a partir de janeiro de 2005. Podem-se visualizar também os dois ciclos da doença, ocorridos em 2002 e 2004. Entre janeiro de 2002 a dezembro de 2008, os meses de janeiro, fevereiro, março, abril e dezembro apresentaram os maiores percentuais dos casos da doença. O mês de janeiro apresentou o maior percentual do período, $15,05 \%$ e o menor percentual ocorreu no mês de outubro $4 \%$.

No período estudado, o envio de amostras para o laboratório foi inferior aos $0,2 \%$ preconizados pela vigilância epidemiológica. $\mathrm{O}$ ano de 2002 , no qual houve o maior número de casos da doença, e os anos de 2006 e 2008, onde não houve nenhum caso registrado, foram os únicos que ficaram dentro do percentual preconizado. Em 2002, 2006 e 2008 os percentuais de envios anuais de material para diagnóstico da raiva canina foram respectivamente, $1,93 \%$, $0,22 \%$ e $0,25 \%$ (Tabela 2 ).

Dentre os 89 cães positivos para raiva canina entre janeiro de 2002 a dezembro de 2008, houve um maior número de machos 59,55\% (53/89) infectados pelo vírus rábico em relação às fêmeas 40,44\% (36/89).
Tabela 1 - Distribuição do coeficiente de incidência e das amostras positivas de raiva canina, segundo ano e tamanho da população canina estimada. Cuiabá - MT janeiro de 2002 a dezembro de 2008

\begin{tabular}{ccccc}
\hline Ano & $\begin{array}{c}\text { População } \\
\text { Canina Estimada }\end{array}$ & $\begin{array}{c}\text { Amostras } \\
\text { Enviadas }\end{array}$ & $\begin{array}{c}\text { Amostras } \\
\text { Positivas }\end{array}$ & $\begin{array}{c}\text { Coeficiente } \\
\text { de Incidência }\end{array}$ \\
\hline 2002 & 73.934 & 143 & 33 & 4,46 \\
2003 & 75.042 & 132 & 19 & 2,53 \\
2004 & 78.600 & 115 & 31 & 3,94 \\
2005 & 80.070 & 147 & 5 & 0,62 \\
2006 & 64.930 & 164 & 0 & 0,00 \\
2007 & 75.717 & 126 & 1 & 0,13 \\
2008 & 87.403 & 194 & 0 & 0,00 \\
\hline
\end{tabular}

Fonte: CCZ - Cuiabá

Em relação à idade, 50,56\% (45/89) dos cães tinham idade acima de dois anos, enquanto que $49,43 \%$ $(44 / 89)$ desses animais apresentaram idade inferior a dois anos.

Uma das principais medidas de controle da raiva canina adotada no Brasil é a vacinação de cães e gatos, realizada anualmente. A vacinação é uma das principais ações de controle de raiva em áreas urbanas, responsável pela diminuição do número de casos de raiva canina e de raiva felina e, consequentemente, da raiva humana. A tabela 3 mostra o percentual de cães vacinados entre 2002 a 2008.

Entre os animais que apresentaram a enfermidade, o maior número, 67,41\% (60/89), foi de cães não domiciliados, os chamados cães errantes. De acordo com Takaoka ${ }^{13}$, esses são animais independentes, vivem soltos nas ruas, por isso são importantes na manutenção e transmissão da raiva urbana. O percentual de cães domiciliados infectados pelos VR foi igual a $32,58 \%$ (29/89). Cães domiciliados são animais totalmente dependentes do proprietário. Saem do domicílio acompanhados e contidos pelo uso de coleira e guia, recebem vacinas e são submetidos a controle clínico periódico. Podem ser considerados de baixo risco para a transmissão do vírus da raiva, porém mesmo sendo considerados de baixo risco esses animais podem ser infectados, se o esquema de imunoprofilaxia não for feito corretamente, ou se a resposta imu- 
Tabela 2 - Percentual de amostras enviadas para análise laboratorial em relação à estimativa da população canina da cídade de Cuiabá - MT, 2002 a 2008

\begin{tabular}{cccc}
\hline Ano & $\begin{array}{c}\text { População Canina } \\
\text { Estimada }\end{array}$ & $\begin{array}{c}\text { Amostras } \\
\text { Enviadas }\end{array}$ & $\begin{array}{c}\text { Percentual de Amostras } \\
\text { Enviadas (\%) }\end{array}$ \\
\hline 2002 & 73.934 & 143 & 1,93 \\
2003 & 75.042 & 132 & 0,17 \\
2004 & 78.600 & 115 & 0,14 \\
2005 & 80.070 & 147 & 0,18 \\
2006 & 64.930 & 164 & 0,25 \\
2007 & 75.717 & 126 & 0,16 \\
2008 & 87.403 & 194 & 0,22 \\
\hline
\end{tabular}

Fonte: CCZ - Cuiabá

Tabela 3 - Estimativa da população canina e distribuição da cobertura vacinal em Cuiabá - MT, de 2002 a 2008

\begin{tabular}{cccccccc}
\hline & 2002 & 2003 & 2004 & 2005 & 2006 & 2007 & 2008 \\
\hline $\begin{array}{c}\text { População Canina } \\
\text { Estimada }\end{array}$ & 73.934 & 75.042 & 78.600 & 80.070 & 64.930 & 75.717 & 87.403 \\
Cobertura vacinal & $86,25 \%$ & $89,91 \%$ & $97,57 \%$ & $84,8 \%$ & $79,7 \%$ & $93,00 \%$ & $88,5 \%$ \\
\hline
\end{tabular}

Fonte: CCZ - Cuiabá

ne do animal à vacina não for satisfatória. Esses fatos podem explicar o percentual de positividade entre os cães domiciliados. A figura 2 mostra o percentual de cães não domiciliados positivos para o diagnóstico da raiva em relação ao número de cães domiciliados.

\section{Discussão}

O comportamento cíclico da raiva, segundo os dados aqui apresentados, pode ser explicado pelo aumento de susceptíveis, como um maior número de cães errantes pelas ruas da capital mato-grossense. A campanha de vacinação em massa, que passou a ser realizada em Cuiabá em duas etapas: vacinação animal em rotina e vacinação animal em campanha "casa a casa", teve como alvo principal vacinar o maior número de susceptíveis possível, resultando assim em um decréscimo de suscetíveis no ano de 2003. Especula-se que o aparecimento de um novo ciclo da doença em 2004 (Figura 1) pode ter ocorrido pela introdução de animais não vacinados, além de maior número de quirópteros não hematófagos encontrados no perímetro urbano da cidade de Cuiabá - MT infectados pelo vírus rábico.

As medidas de prevenção e imunoprofilaxia adotadas pelo Centro de Controle de Zoonoses de Cuiabá - MT começaram a surtir efeito a partir do ano de 2005 , onde os números da doença declinaram de forma evidente, desde 2008 não há registros de casos da doença transmitida por cães na cidade (Figura 1). A redução dos casos de raiva canina na cidade e Cuiabá - MT a partir de 2005 é semelhante ao que acontece no Brasil, onde se observa uma nítida diminuição nos casos transmitidos por esses animais. Essa diminuição é consequência das diversas atividades realizadas no âmbito municipal, destacando-se as campanhas de vacinação antirrábica animal, bloqueios de foco, captura de animais errantes, tratamento profilático antirrábico humano, vigilância mais sensível e ampliação da capacidade de diagnóstico laboratorial.

Corrêa e Corrêa ${ }^{11}$ afirmam que não há variação da patogenicidade em relação ao clima e estação do ano, porém o autor explica que na primavera e verão as 
Coeficiente de Incidência

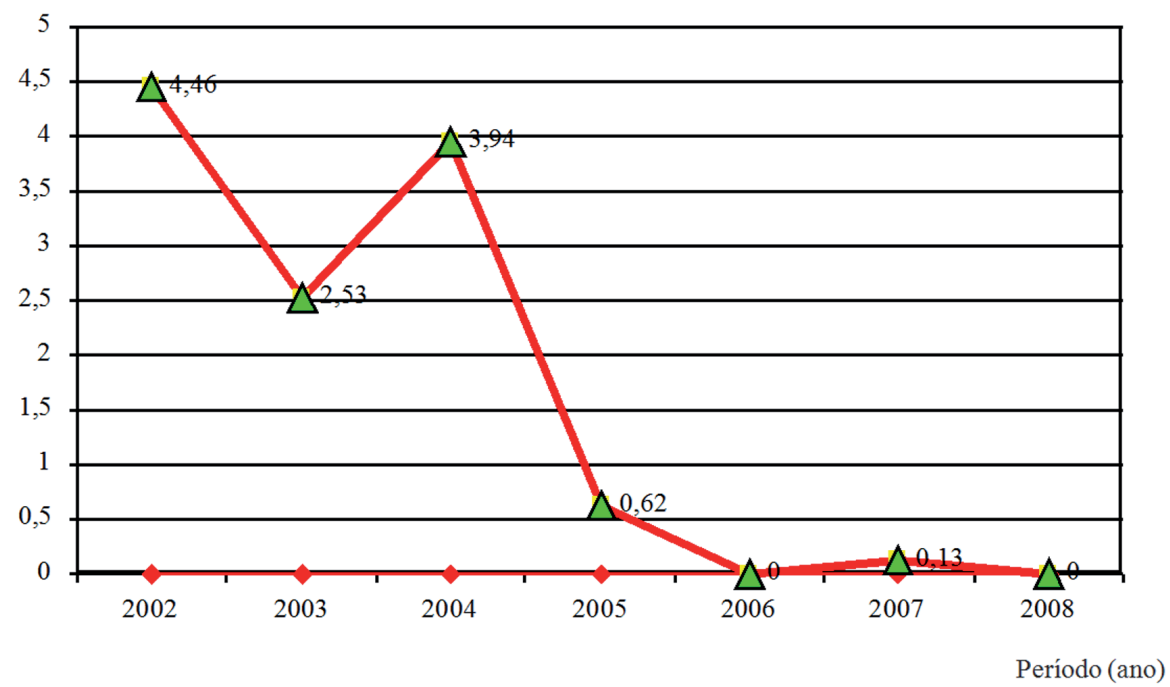

Figura 1 - Distribuição dos casos de raiva e coeficiente de incidência no município de Cuiabá - MT de janeiro de 2002 a dezembro de 2008 (Fonte: CCZ - Cuiabá - MT)

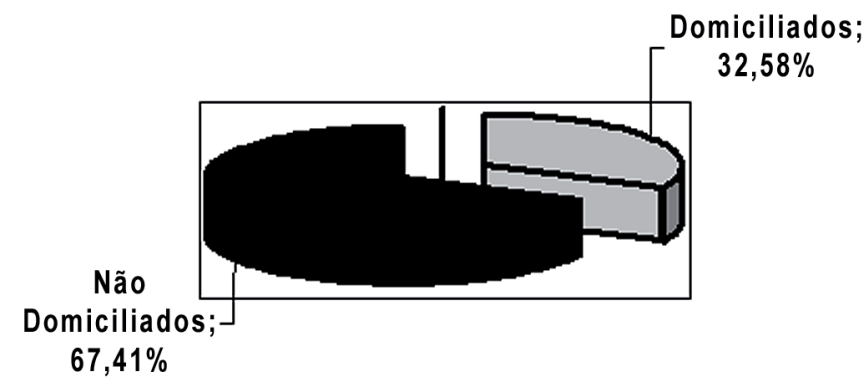

Figura 2 - Percentual de cães infectados pelo VR em relação ao grau de domiciliação (Fonte: CCZ - Cuiabá - MT)

taxas de incidências são maiores devido ao cio das cadelas (cio de primavera e verão), havendo maior aglomeração de animais, disputas, brigas e mordeduras, em discordância com os picos da doença que ocorreram em Cuiabá, sendo maiores nos meses de janeiro (15,05\%), abril (14,14\%), e dezembro (13,69\%).

A Vigilância Epidemiológica preconiza o envio de amostras anual sistemático de $0,2 \%$ da população canina estimada, para realização de diagnóstico laboratorial, independente da situação epidemiológica da região. Municípios com menos de 20.000 habitantes devem encaminhar pelo menos 12 amostras ao ano. $\mathrm{O}$ que se pôde observar é que em Cuiabá entre os anos de 2003, 2004, 2005 e 2007, os índices de amostras enviadas para análise laboratorial foram respectivamente: $0,17 \%(132 / 75.042), 0,14 \%$ (115/78.600), $0,18 \%$ (147/80.070) e 0,16\% (127/75.717) (Tabela 2), ficando abaixo do percentual de $0,2 \%$ preconizados pela Vigilância Epidemiológica, mostrando assim que durante esses anos o número de amostras foi insuficiente para o monitoramento da circulação viral. O encaminhamento de amostras para o diagnóstico da raiva é importante, pois permite a análise da situação epidemiológica da região e se há ou não vírus circulante 
naquela localidade. $\mathrm{O}$ envio sistemático de amostras para diagnóstico laboratorial deve ser implementado, pois, para que um local passe ser considerado como área geográfica com raiva canina controlada, é necessário que não haja a ocorrência de casos da doença em cães causada pela variante do vírus rábico própria da espécie canina.

$\mathrm{O}$ que pode explicar o maior percentual de machos $59,55 \%$ (53/89) contaminados em relação às fêmeas $40,44 \%$ (36/89) é que, de acordo com dados do Setor de Vigilância a Saúde e Ambiente da Secretaria $\mathrm{Mu}-$ nicipal de Saúde de Cuiabá, há um maior número de cães machos em relação às fêmeas no município de Cuiabá - MT, e os mesmos estão mais sujeitos a raiva por seus hábitos de domínio e disputa por fêmeas.

Em Cuiabá, os cães infectados pelo vírus rábico eram animais jovens, onde 50,56\% (45/89) estavam na faixa etária de 2 a 7 anos e 49,53\% (44/89) apresentavam idade entre 1 e 2 anos. A pequena diferença $(1,13 \%)$ entre os cães infectados com faixa etária de 1 e 2 anos e de 2 a 8 anos mostra que a raiva canina é transmitida entre os animais independente da idade. Ressalta-se que a primovacinação é indicada a partir dos três meses de idade. A dose de reforço deve ser administrada de 30 a 45 dias após a administração da dose inicial, o que não ocorre em campanhas públicas. A revacinação periódica deve ser anual. Deve-se lembrar de que na faixa etária de maior fertilidade (1 a 4 anos) há maior contato e aglomeração entre esses animais, e, consequentemente maior possibilidade de transmissão do vírus rábico nessa população, já que, devido ao período de incubação relativamente longo, os animais infectados podem transmitir o vírus por alguns dias antes do aparecimento dos sinais clínicos.

\section{Referências}

1. BRASÍLIA. Ministério da Saúde. Coordenação de controle de zoonoses e Animais Peçonhentos. Manual de normas
No Brasil, as campanhas de vacinação antirrábica em pequenos animais são tradicionalmente planejadas e avaliadas considerando-se estimativas de população canina, calculadas com base em recomendações feitas pela Organização Mundial de Saúde $(\mathrm{OMS})^{12}$ e pelo Instituto Pasteur ${ }^{13}$ de São Paulo, Brasil. Para o controle adequado da raiva em áreas urbanas, recomendam uma cobertura vacinal mínima de $80,0 \%$ da população canina total. No Município de Cuiabá, no período de 2002 a 2008 exceto por 2006, a cobertura vacinal ficou acima dos $80,0 \%$ preconizados pela OMS. Esse percentual permitiu um bloqueio do vírus rábico na população canina da cidade de Cuiabá, levando os índices de positividade a zero a partir do ano de 2008.

\section{Conclusão}

Os custos decorrentes das endemias de zoonoses para o sistema de saúde pública, bem como o sacrifício de animais, demonstram a necessidade de um programa constante de vigilância e combate às zoonoses em áreas urbanas. Em Cuiabá, os anos de 2002, 2003 e 2004 foram considerados críticos em relação à contaminação de cães pelo vírus rábico. A partir do ano de 2006, com as medidas adotadas pelo Centro de Controle de Zoonose de Cuiabá, os índices da doença decresceram, mostrando que as medidas adotadas pelo órgão surtiram efeito, promovendo um maior controle da doença.

O controle reprodutivo através de programas alternativos de esterilização cirúrgica de cães é apresentado como uma alternativa para tentar conter a reprodução e evitar o sacrifício de animais.

As campanhas de vacinação em massa são fundamentais para a imunização de maior número de animais possível.

técnicas para profilaxia de raiva em humanos. 2. ed. Brasília (DF):MS, 1996. 
2.ACHA, P. N.; SZVFRES, B. Zoonosis y enfermidades transmissibles comunes al hombre y los animales. Washington: Organización Panamericana de la Salud, 1986. p. 502-526.

3.FENNER, F.; BACHMAN, P.A.; PAUL, E.; WHITE, D.O Veterinary virology. 2nd. ed. San Diego: Academic Press, 1993. $666 \mathrm{p}$.

4. CARVALHO, W. O.; SOARES, D. F. P. P.; FRANCESCHI, V. C. S. Características do Atendimento Prestado pelo Serviço de Profilaxia da Raiva Humana na rede Municipal de Saúde de Maringá-Paraná, no ano de 1997. Informe Epidemiológico do SUS, v. 11, n. 1, p. 25-35, 2002.

5. PASSOS, A. D. C.; CASTRO E SILVA, A. A. M. C.; FERREIRA, A. H. C.; SILVA, J. M.; MONTEIRO, M. E.; SANTIAGO, R. C. Epizootia de raiva na área urbana de Ribeirão Preto, SP, Brasil. Cadernos de Saúde Pública, v. 14, n. 4, p. 735-740, 1998.

6. MIRANDA, C. F. J.; SILVA, J. A.; MOREIRA, E. C. Raiva Humana transmitida por cães: áreas de risco em Minas Gerais, Brasil, 1991-1999. Caderno de Saúde Pública, v.19, n. 01. 2003. p. 91-99.
7. CUIABÁ. Secretaria Municipal de Saúde. Plano Municipal de Saúde, 2002 - 2005. Cuiabá: SMS, 2002.

8.IBGE. Instituto Brasileiro Geografia e Estatística. Censo demográfico 2010. Rio de Janeiro: IBGE, 2010. Disponível em: <http://www.ibge.gov.br/cidades/>. Acesso em: $6 \mathrm{dez} 2010$.

9. IBGE. Instituto Brasileiro Geografia e Estatística. Censo demográfico 2007. Rio de Janeiro: IBGE, 2008. Disponível em: <http://www.ibge.gov.br/cidades/>. Acesso em: 6 dez 2010.

10.UNIVERSIDADE FEDERAL DE MATO GROSSO. Disponível em: <http://www.ufmt.br/>. Acesso em: 6 dez 2010.

11.CORRÊA, W. M.; CORRÊA, C. N. M. Raiva. In: CORRÊA, W. M.; CORRÊA, C. N. M. Enfermidades infecciosas dos mamíferos domésticos. São Paulo: Medsi, 1992. p. 609-628.

12. OMS. Organização Mundial de Saúde. O controle da raiva: Oitavo relatório do Comitê de especialistas da OMS em Raiva. Organização Mundial de Saúde: tradução Fernando Melgaço de Assunção Costa. p. 2-159 Goiânia, Goiás 1999.

13.TAKAOKA, N. Raiva. São Paulo: Instituto Pasteur. Disponível em <http://www.institutopasteur.br.> Acesso: em 11 abr. 2010 